\title{
Refugee research in the shadow of fear
}

\author{
Pablo S. Bose
}

Accepted: 16 November 2020/Published online: 28 November 2020

(C) Springer Nature B.V. 2020

\begin{abstract}
What does it mean to conduct communitybased and praxis-oriented research at a time when those whose lives you study and with whom you work are the subjects of increasing levels of xenophobia, marginalization, and demonization? How does one conceive of research ethics, of the relationship between the roles of scholars, teachers, and citizens in light of such dynamics? In what ways can scholarship help to intervene in the world around us, in particular to improve the perception and amplify the voices of marginalized groups and individuals? This paper considers these issues in the context of research ethics and the growing field of community geography. I draw in particular on an example from a multi-year study of refugee resettlement in non-traditional destinations across the US. When the study began, refugee policies and settlement patterns were little known to the general public in the US. Since then, refugees and migration more broadly have become increasingly prominent and controversial worldwide. In this paper I explore some of the challenges regarding collaborations between university researchers and community partners, highlighting the tensions exposed through the use of the visualization technique known as Photovoice, meant to provide alternative
\end{abstract}

P. S. Bose $(\bowtie)$

Department of Geography, University of Vermont, 200

Old Mill Building, 94 University Place, Burlington,

VT 05405, USA

e-mail: pbose@uvm.edu perspectives on ideas for urban change amongst participants. I also consider some ideas for steps to address these challenges, including the building of networks and training for researchers and formalized partnership processes for community groups.

Keywords Refugees $\cdot$ Research ethics $\cdot$ Community geography $\cdot$ Photovoice $\cdot$ Xenophobia

\section{Refugee research in the shadow of fear}

My friend the professor!" exclaimed one of the participants in the PhotoVoice session about to begin, "What do you have for us this time? What do you want to learn about? What we eat? Where we go? How we get there? I hear you want us to take some pictures, is that right? What are you going to do with them? Hey, as long as you give us those giftcards, right? I'm trading you these stories for a giftcard, am I right? But they're still my stories and you gotta do right by me when you tell them.

Such exchanges are not uncommon for me in my work, especially with community members who I have encountered across multiple contexts and perhaps even multiple projects. Some of these projects have been initiated by me and others by my community 
partners. It has taken long to build trust and relationship so that this kind of banter is not fraught but rather at least superficially playful. But at the same time, it reminds me of the complex dynamics that researchers must keep in mind when we enter the field and work with diverse communities. Research ethics is about so much more than certification by an IRB or other kinds of ethical review. This is especially true when the topics and communities involved might be made vulnerable-either by the questions being asked or by the process through which information is gathered, analyzed and disseminated. I have thought extensively about these questions in the context of my own work on refugee resettlement in non-traditional destinations across the US. When I began my research, refugee policies and experiences were relatively unknown to the general public in the US, but migration and immigration have since become polarizing and controversial topics worldwide. The relationships between researchers such as myself and the refugee communities I work with have become more important to scrutinize and theorize-what, indeed, is it that I ask of research participants? How do I try to address the power dynamics and imbalances between us? What protections can (and do) I offer to them? What benefits may accrue from working with me?

Developing - and interrogating-such relationships is both crucial and especially challenging in a context where immigrants and refugees have become increasingly demonized, not only in the US but globally - seen as undeserving of protection, as the embodiment of cultural change, as security threats, or in other negative ways. Globally, the number of those forcibly displaced has grown, doubling from approximately 35 million people in 2010 to over 70 million people in 2020 (UNHCR 2020). Yet during the same period relief and especially third-country resettlement programs that have traditionally placed refugees in 'safe' countries in the Global North have gone in the opposite direction, shrinking considerably and in some cases being suspended or closing entirely (Bose 2020). In the US, for example, since assuming office, the Trump Administration has cut the US Refugee Admissions Program from 120,000 planned refugees in 2017 to 18,000 in 2020 , of whom less than a third will actually be resettled due to additional COVID-19 restrictions. A number of factors-violence overseas and at home, the tremendous increase in global refugee numbers, and the exceptionally divisive nature of a national election campaign and tumultuous first years of the Trump presidency-have served to bring to the fore and politicize refugee resettlement in new and often unsettling ways. Public officials have placed the national program under new scrutiny while others have called for a halt to it; it has been severely constrained and shrunken as a result. Rampant Islamophobia, racism, and anti-immigrant rhetoric has seen refugees targeted as an unwelcome presence in many places.

The questions I consider in this paper are thus twofold: how does one conduct community-based research in this political moment and how does one attend to the necessary self-critique of research ethics and positionality regardless of the specific context? What does collaboration mean? What kinds of benefits accrue to participants and to researchers? How does one navigate the overlapping, constructive and competing interests-personal, professional, institutional and political — that bracket our work? As stated above, it is not a new challenge to ask ourselves how we work with and on/about marginalized and targeted communities, even if the questions might seem more relevant or pressing in particular historical moments. In this paper, I consider some of the complexities and strategies for intervening in and improving the knowledge of the resettlement program and the lives and contributions of refugees themselves, drawing as many lessons from the failures I have experienced as successes to learn from. I begin the paper with a review of the framework of community-based research within which I situate my work with particular attention to the technique of Photovoice used in my study. Next, I describe the contexts within which I work in Vermont. The remainder of the paper is devoted to a description and analysis of a particular example from my research - an attempt to understand participant perspectives on urban space-which serves to highlight the complexities that engagement brings. This activity is a visualization exercise meant to strengthen refugee participation in neighborhood planning processes and in using this example I describe not only the logistical challenges in carrying it out but also the criticisms that participants raised regarding their own vulnerabilities in the project in this political moment. I conclude the paper by offering some suggestions for thinking about ethical practices in studying, teaching and learning with refugee communities in the contemporary moment. I draw in 
particular on the steps taken by refugee advocacy organizations that I work with to better manage and guide their interaction with researchers as a whole, whether with the university, researchers, or students and also detail some preliminary attempts by my colleagues and myself to develop structures to support collaborative research with refugees.

Research ethics, community geography and photovoice as method

The challenge to act ethically, respectfully and collaboratively as researchers is not a new one. Many disciplines have long grappled with an often-fraught relationships between scholars, the academy and research subjects/the subjects of research. While there have been advances and more self-reflexivity on the part of many researchers, the tensions-especially for marginalized communities who find their perspectives, stories and lives of interest and value to many outsiders-remain. Communities being studied can find themselves receiving negligible (or no) benefits from the projects in which they participate, often leading to a sense of what has been called 'research fatigue' (Clark 2008; Sukarieh and Tannock 2013; Neal et al. 2016). In some fields these kinds of dynamics have been explicitly critiqued-in anthropology, political science, area studies, and geography, for example, some scholars have asked what role their own disciplines have played in constructing, reinforcing and reifying relations of power, privilege, and oppression (Mirsepassi et al. 2003; Hale 2006; Fujii 2012; Cronin-Furman and Lake 2018; Kirsch 2018). How might ethnographic research, for example, objectify, commodify and exoticize 'other' cultures and lives (Lester 2016)? How might participatory mapping projects with indigenous communities paradoxically serve neocolonial projects that undermine those same groups' interests (Wainwright and Bryan 2009; Mollett 2013; Bryan 2016)? In what ways might activists and scholars from within marginalized communities find themselves compromised or co-opted by the research process itself (Villenas 1996)?

These are just some of the concerns raised by the wide range of research projects and processes that we see in the world today. Such concerns are neither new, nor are they limited to the most egregious excessesforced experimentation, a lack of consent by subjects, or extractive practices for example - that led to the development of formalized institutional protections in the first place. But such protocols, that dominate and are structured by medical and social science research in particular, often do not call into question the relationships between scholarly inquiry and deeply embedded structures of inequity, oppression, empire, colonialism, power and privilege that are reproduced and reinforced by them. As Dyer and Demeritt (2009) suggest, the ubiquity of the medical model in ethical review and protection presents many problems for social science and especially action-oriented research. Too often the risks of liability for the academic institution lead to cautious and often awkward and counter-productive interactions between researchers and researched. The requirement for ethical review is thus often at odds with the demands that many scholars-especially feminist and postcolonial scholars-have made of their own practices and those of their colleagues. Often the most critical components of such demands - of exploring positionality and the provenance and outcomes of specific methods-are sidelined, as Sharp (2005) suggests in the adoption of inclusive gender politics over a feminist political project within geography. Even amongst those scholars who aim to decolonize their methodologies, be self-critical about their own positionality, and embrace collaboration in their approach, many challenges remain.

How does one avoid what Rose (1997) cautions as the god/goddess-trick of assuming the omnipotence of 'knowing' how to 'do research properly' and dispense advice and render judgement unto others? How does one not reify fieldwork as a site of failure from which only the writer/researcher can extract lessons and knowledge? I thought about this a lot as I revised earlier versions of this paper and realized the ways in which my representation of the project, processes and participants told a different set of stories-often in an unintended and unwelcome tone-than the one that I had imagined. Such representations are immensely and intimately important. Valentine (2005) reminds us that recovering and integrating a sense of purpose is central to the ethical commitments of human geographers and that intellectual questions should not displace political concerns. Thus, while it may seem obvious that a project focused on the diversity of refugee lives and perspectives should not endanger the participants, so too is it crucial that the description of such research should not be reductive, monolithic and 
didactic. As Kyriakides et al. (2018) suggest, there is real harm in narrow and stereotypical representations of refugees, as well as how their stories are reproduced and deployed by academics as much as by popular culture. Or as Landau (2019: 26) reminds us in the context of refugee research:

However well meaning, research partnerships also come with substantial risks of heightening inequality and becoming complicit in global strategies of migrant containment...[and]...enact and expose the inequalities, structural constraints and historically conditioned power relations implicit in the production of knowledge.

Realizing that my original retelling of the lessons learned from this project had been blind to-or at least downplayed-such dynamics show the ways in which they are deeply embedded within researchers like myself who claim to make them front and center. The primary methodological tradition in which this project has been grounded, after all is participatory, actionoriented research utilizing a mix of qualitative techniques-interviews, surveys, and community mapping workshops. Its goal has been to further our understanding of the phenomenon of refugee resettlement in new destinations, refine policymaking regarding these trends, and improve the outcomes and lived experiences of refugees and receptions sites alike. Participatory research provides both the conceptual framework and the methodological tools to help guide the inquiry. As Kindon and Elwood (2009: 21) describe in their overview of the research tradition.

[its] goal is not just to describe or analyse social reality, but to change it... [commonly], research takes place within a group setting involving the academic researcher as a facilitator of focusgroup discussions, interviews, diarying and participatory techniques such as community mapping and diagramming.

Participatory approaches have long been influential in a number of disciplines seeking to connect scholarly inquiry actively with the subjects of study, communities being investigated, and in service of broader goals to better the world. We see numerous examples of this orientation, from the participatory rural appraisal (PRA) strategies of international development work beginning in the 1960s (Chambers 1994) to the catalytic nature of community-based projects in social work (Rubins and Babbie 2011), from attempts to destabilize hierarchies between researcher and researched in education (Cammarota 2017) to the interventionist goals of Participatory Action Research (PAR) in a range of disciplines (Bengle and Schuch 2018).

Within human geography, participatory research has had an equally longstanding and significant history (Kindon et al. 2007). Pain (2004: 652) describes it as a "collaborative and nonhierarchical approach which overturns the usual ways in which academics work outside universities." She highlights in particular the contributions that feminist and radical geographers have made in terms of making research more reflexive and self-critical, and as a result both insightful and more socially relevant. More recently, the sub-field of 'community geography' has evolved to focus on a multi-scaled and nuanced approach to working with/in various settings. Hawthorne et al. (2015: 24) have defined community geography as "a process, set of methods, and collaborative framework that uses spatial thinking and geographic approaches that enable academics and communities to engage in inclusive, mutually beneficial, shared research experiences." Qualitative and critical GIS have played an important role in shaping community geography especially as it has developed in opposition to a sense of GIS as positivist and instrumentalist. Scholars such as Wilson (2009) has suggested that instead qualitative GIS represents a powerful and critical mode of inquiry, one that can help us answer important research questions while simultaneously engaging with the issues of positionality and power that go into both analyzing and representing spatial knowledge. We have seen an increasing number of studies take on exactly this challenge, including ones examining healthcare inequality in low-income neighborhoods (Hawthorne and Kwan 2012), emergency food needs in underserved areas (Robinson 2011), citizen participation in urban planning (Merrick 2012), and actionoriented research with 'hidden' or potentially marginalized communities (Browne 2005), amongst many others.

The approach that community geography thus advances is one that puts reciprocal relationships between researcher and researched at the core. As Holt et al. (2019: 391) describe it in the context of disabilities research: 
Engaging with voices from the margins engenders a political imperative to ensure that research challenges rather than reproduces marginalised positions in society and space, and that research is inclusive of people's experiences and transformative in challenging the status quo.

Or as Robinson et al. (2017: 5) suggest, "community geography particularly focuses on work which confronts existing power structures to allow underresourced communities to better address community development challenges." Such publicly-minded and engaged research is especially relevant in the current political moment. Alderman and Inwood (2019: 149) argue that.

Although public intellectualism can take many
forms and can happen in the most surprising of
places, we often find that many academics treat
the conversation and conception of public
engagement as a kind of one-way street where
our knowledge flows forth. The reality is that the
most fruitful public engagements include the
sharing of information and often are a more
collaborative process than most research and
writing projects. Therefore, it is important to
actively cultivate and seek out long-standing and
fruitful relationships and for us to move away
from the one and done model of public
engagement.

Robinson and Hawthorne (2018) point out, however, that community geography remains itself on the margins of the discipline and the nature of its outputoften disseminated slowly or in non-scholarly venues-may leave those who adopt these approaches from within the academy vulnerable in increasingly precarious faculty positions. Having already gained tenure, I have been insulated from at least some of this kind of vulnerability, though the pressure to publish remains for further advancement. Yet I am able to exercise more autonomy in selecting subjects to study and I can utilize a wider and more diverse set of methods within my projects without as much question. Using an interdisciplinary method like Photovoice (most commonly found in public health and planning research) for the purposes of this project, therefore, becomes easier.

Photovoice is a well-established method that has been used within community-based contexts and community geography in particular. While there are different variations on what Photovoice looks like, at its core it is a technique that involves asking participants to use photographs, images and other forms of visualizations to respond to a series of questions or prompts provided by researchers. The intention is to illuminate or highlight perspectives, ideas and insider knowledge that might otherwise remain hidden to outsiders. There are usually three stages common to most Photovoice projects: (1) creating and documenting a series of images (often responding to prompts or questions provided by the lead researchers), (2) reflection and discussion on the images and why they were chosen by the participants and research team, and (3) an exhibition or dissemination of the images and knowledge to a wider community as a way of providing interventions and changes in discourse, policy and practice (Wang and Burris 1997). Photovoice has been used effectively in many other instances as a community-based participatory research method to help intervene in specific issues or dynamics. Photovoice has been especially powerful in reimagining urban planning (Borowiak et al. 2018), immigration issues in Europe (Rania et al. 2014), children's perception of space (Burke et al. 2016; Greene et al. 2013; Fusco et al. 2012), gender and homelessness (Fotheringham et al. 2014), sexuality and space (Bain et al. 2014), racialization processes (Pérez et al. 2016; Goessling 2018) and public health (Sanon et al. 2014) amongst many others.

Yet the increased popularity of Photovoice as a technique has also raised many of the same questions asked of research (and community geography) more generally. Murray and Nash (2017) contend that there is a lack of theorization of the method, that the use of images is often poorly understand by participants, that confidentiality of subjects and participants is often compromised and that the actual outcomes of projects can be limited. In her study of the use of the technique to understand HIV/AIDS interventions in a small town in South Africa, Harley (2012) reminds us that photography remains a practice of power. She asks whether there is an inherent issue of exploitation even when images are provided by consenting participants due to the power imbalance between them and the researcher. In Derr and Simons' (2019) review of the use of Photovoice in a range of environmental research studies, the authors argue that the effectiveness of the technique has been overstated by the dissemination of 
successful projects a lack of discussion of when it has not worked as well. Researchers working in the field of mental health (Creighton et. al. 2018) have raised the concern of both retraumatizing participants and of causing vicarious trauma to viewers of the exhibition component of the technique when Photovoice is used to explore particularly painful and sensitive subjects. In their study of including older populations in city planning and social inclusion in the UK, Ronzi et al. (2015) question how truly comprehensible the use of Photovoice is to participants as well as to how well certain complicated contexts can be represented by or translated into a visual method such as this. Da Silva Vieira and Antunes (2014) suggest in their reflections on the use of Photovoice in participatory planning processes that there are real issues with the reliability of the method, especially in the biases and agendas that participants may foreground in their choices. The skewed nature of the sample photos taken by their participants also reflected the difficulties they had in recruitment due to the lack of familiarity with and therefore trust in the method.

Despite such criticisms, there are also reasons for the popularity of the method, which of course has a much longer history than its formalization as Photovoice. Other versions-photo elicitation, participatory visual methods, image-based storytelling, participatory photography, photo novellas-exist and in many cases predate the Photovoice technique. But there can be an ease and straightforwardness to this particular version which is appealing to researchers. At its best, Photovoice can allow for new and different perspectives to influence perceptions of a particular phenomenon, practice or place and may even affect decision-making. In Randa Nucho and Nahm (2018)'s analysis of parent activism in an elementary school in Los Angeles, for example, marginalized groups were able to use Photovoice to reframe issues of importance to them. Language was an especial initial barrier in this study, one that still needed to be addressed in the reflection and discussion stage of the project, but the use of participant-taken images helped to start and guide those discussions more effectively than interviews or surveys undertaken previously had. And in Castleden, Garvin and the Huu-ay-aht First Nation's (2008) project on health and environmental issues within an indigenous community in Canada, the research collaboration was viewed by participants as highly successful. Participants commented in particular on the careful attention to issues of power imbalances, trust-building, a sense of ownership in the research process, and an understanding of Photovoice as a culturally-appropriate method-an especially interesting outcome given the fraught history of indigenous populations with the use of images taken of or by them. It is also clear from the researchers' reflections on this project that their use of Photovoice was as successful as it was because of their modification of the technique to fit their particular community context.

With such caveats and lessons in mind regarding research ethics, community geography and Photovoice as method in mind, let me turn to an example from my own research. I begin by explaining the context and then exploring my experiences of using Photovoice.

\section{Refugees in vermont}

The research I describe in this article is part of a multiyear, multi-site inquiry into the experience of refugee resettlement in non-traditional places in the US and Europe, with particular attention to my home study site of Vermont. The impetus for undertaking this inquiry arose out of personal, professional and community interests. My arrival in Vermont as a migration scholar, an urban geographer, and as a person of color were jarring in many ways-studying migration in a place with few migrants, studying cities in a place with few metropolitan areas, and living as part of the less than $2 \%$ of the population that identified as non-white. But my questions regarding the nature and outcomes of the refugee program in Vermont were not ones of personal curiosity alone-it was not only I who wondered why refugees were being placed in Vermont, what happened to them upon arrival, and what happened to the towns that received them. State and local governments, service providers, resettlement agencies, and refugee advocacy groups themselves all had had similar questions well before my arrival. They had voiced many of these to me as well through the multiple interactions I had with them over the course of my first few years in Vermont. I was fortunate to secure funding for a number of different projects-on transportation and mobility, on food and culture, on employment and housing and many others as welland pursue inquiries into the nature of each. 
When I began my research, I was one of a handful of colleagues at my institution and indeed in my state who were looking specifically at refugee experiences. That has, however, changed dramatically-especially over the past 5 years - as increasing numbers of faculty and especially students have sought to put refugees at the center of their work. This is not surprising; immigration is, after all, one of the most contentious, charged and defining issues of our current age. And in Vermont, refugees are the main face of immigration-other than a small population of migrant farmworkers helping to sustain the dairy industry in rural areas - refugees represent the kinds of migration-related demographic change that are so visible in other parts of the country (Bose 2018). Vermont is unlike many other places in the US. It is one of the whitest states in the country, with a mostly rural population, an aging population, and few cities of any size (US Census Bureau 2020). It has also historically been a destination for European immigrants, especially through the late 19th and early 20th centuries, but has attracted few who have come in larger subsequent waves from Asia, Africa and Latin America and the Caribbean from the 1960s onward. Of the immigrants who are in Vermont, a substantial proportion have arrived since 1980 through the US Refugee Admissions Program (RPC 2020). The largest of these groups are Bhutanese who arrived between 2008 and 2018, followed by Bosnians between 1995 and 2005, Vietnamese (1985-2000) and Somali Bantu and Congolese communities (2005present). With the exception of Bosnians who can be linguistically and religiously distinct but may appear phenotypically white, the majority of refugees in Vermont are noticeably 'different' amidst an overwhelmingly white population.

The treatment of refugees within Vermont has been generally positive during the period that the resettlement program has been active. The program has been consistently funded and there appears to be strong popular support for accepting refugees especially in Vermont's largest cities and towns (Bose 2020). Even in the face of the attacks on the USRAP at the national level and by a multitude of political commentators, within Vermont the resettlement program has been identified as a priority by the state and by multiple municipal governments. Yet a backlash against refugees exists even in this politically progressive state, as seen most notably in the controversies that erupted in 2016 when a new resettlement site was proposed in Rutland, its third largest town (Bose 2018). White nationalist and identitarian groups have repeatedly targeted refugees in their propaganda efforts in Vermont as undesirable and unwelcome. While such hate-groups represent a small minority of Vermont residents, the strength of such toxic voices added to the divisive national discourse combines to make the landscape more threatening and uncertain for refugees as it does for other immigrant populations. Several ballot measures in different Vermont cities to allow refugees (who are ineligible for citizenship for the first 3-5 years after arrival) to vote in municipal elections have failed. And African and Asian youth from refugee backgrounds have complained of racist treatment, stereotyping and profiling for years (Bose 2020).

Refugees in Vermont therefore find themselves a popular subject for both proponents and opponents of immigration policies and in-migration more broadly. This visibility is complicated even when positive; support for refugees can be seen in the public rallies, successful donation drives and editorials in local newspapers, but even such support can come with strings attached. Refugees and the organizations that work with them find themselves fielding constant questions regarding their lives and their desires. Some of these come from the general public or from different parts of the media and can reify the image of the refugee as exotic and other and can come across as uninformed. But skilled researchers too-especially those interested in migration and acculturation-often turn to local refugee communities to answer a diverse array of questions. Each year these communities find themselves asked to participate in more surveys, more interviews, more focus groups, and more research studies. They are often asked questions by new researchers that they have been asked many times before-about food security, or housing, or education or healthcare, or indeed all of these. And as one of the key faces of 'diversity' in a putatively homogenous state, refugees also get asked to define or represent the 'New American' experience, to participate in innumerable 'equity and inclusion' initiatives and explain what racialization means to them. Yet it is often unclear what the benefits might be for the refugees themselves or whether there is to be compensation for their time, their efforts or their ideas. I have been as guilty of such over-researching as any other, though I 
try to build in recognition of the 'asks' that I am making of collaborating organizations and research participants. Including stipends for participants for their time or paying for staff time for organizations are only two ways to acknowledge their contributions, but as the following example shows, such modifications still do not always address the issues of ethics, power and outcome discussed earlier in this paper.

Photovoice and the challenges of communityengaged research

As indicated in the previous section, this was not my first project with refugees, nor even the first time I had used Photovoice with them. Having lived and worked in Vermont for over a decade and having partnered with the two main resettlement organizations for the entirety of that time, I had built relationships and trust through these years. I have had as much failure as success - projects that did not lead to the interventions hoped for and others whose results had been minimal. But my service during this period as a transit commissioner, a housing commissioner and a public works commissioner in the county meant that I also had the opportunity to translate some of my research to public policy outcomes in various ways.

It was with this potential in mind that I embarked upon a project that fit within the broader umbrella of my study of refugee resettlement in smaller, nontraditional immigrant destinations in the US, and what I perceived as community need. The intention was to better understand the perspectives of residents regarding the character, use and transformations of urban space within the two largest refugee neighborhoods in Vermont's most populous metropolitan area. Its main city of Burlington and the adjoining suburb of Winooski contain the greatest concentration of refugees. The neighborhoods in which they have been placed are shared with college students, other lowincome residents and over the past decade in particular have been undergoing significant and controversial changes. To proponents this process is urban revitalization, to critics it is gentrification. Some residentsmainly native-born and white-have organized protest movements against these changes, yet the voices of refugees have been notably absent from most discussions and debates.

The city governments and their respective planning departments have been especially eager to incorporate such voices into the planning process. They have provided interpreters at public meetings, translated (some) documents into relevant languages, launched surveys and tried to do outreach to solicit feedback on planned developments. The results have been mixed, with refugee participation still low, mainly due a lack of time to participate as well as little sense that their voices would in fact be able to engender change. My project thus attempted to provide a new avenue for input, feedback and collaboration for refugees and to understand their perspectives on the neighborhoods in which they lived. The project was straightforward and followed the basic Photovoice model: have participants take photos in response to research-team-developed prompts, provide a space to discuss the images with participants, and then disseminate the results both internally and externally. I planned to recruit 20 individuals who lived in each of the two neighborhoods with the greatest numbers of newly arrived refugees in Vermont to and ask them to take photos of and discuss their views about their neighborhoods. The purpose was two-fold; to help the research team understand the ways in which new arrivals might be reshaping the neighborhood, and to better incorporate the voices of residents into local planning processesproviding reports and updates to neighborhood planning assemblies and the community and economic development offices of each city, and hosting a public exhibition of images selected by participants as a final outcome for the project. An additional goal was to provide information to participants and refugee communities more generally on how they might serve on local municipal boards, attend and engage in different planning events, and perhaps consider running for elected office themselves.

My knowledge of the two particular refugee neighborhoods was grounded in spatial analysis my team and I had been conducting for several years. We had spent several years mapping community assets within these neighborhoods, identifying new businesses, community gathering spaces, social services, religious institutions, grocery stores, public resources, public space, and food and drink amongst other important spaces. Yet our understanding of all of these was only ever going to be partial given our lack of embeddedness within the communities. We thus turned to residents to better understand their context. As mentioned previously, these are neighborhoods in flux, with a slow but steady increase in home 
ownership and decline in rental properties. Burlington and Winooski do not embody gentrification in quite the same way that the stereotypes in many larger cities might suggest, with coffee shops and boutique businesses displacing long-term residents (though that too has happened at a smaller scale). Instead, the changes have been more subtle-smaller shifts from renters to owners, for example, or municipal investments in mixed-use housing and businesses rather than affordable housing. Especially in city-led projects in both Burlington and Winooski, a common complaint has been a lack of local involvement in decision-making. This has been especially true for refugees. The lack of involvement by new arrivals has been identified by both them and neighborhood planning assemblies as serious and unaddressed problems, with as noted previously very few refugee arrivals taking part in public meetings and other outreach efforts designed to add resident voices and priorities to the process. Adding translated materials and interpreters to meetings has done little to boost participation. Accordingly, my research team and I decided to use the tool of Photovoice to add more perspectives on what is and is not valued within these neighborhoods.

Recruiting participants for such a project was not challenging at first. People within the communities we spoke with liked the visual aspects of the project and the promise that this might lead to actual changes that they desired. The project itself also seemed different than what they were used to-not the usual interview, focus group or survey, but the opportunity to be somewhat more creative. It also seemed rather easy: walk around your neighborhood and take pictures. We had offered the following four prompts to guide their activity:

1. Take 3 pictures of things you want to see changed in your neighborhood

2. Take 3 pictures of things you want to see stay the same in your neighborhood

3. Take 3 pictures of things that represent USA/ Vermont to you in your neighborhood

4. Take 3 pictures of things that represent home/community to you in your neighborhood

Participants then sent these pictures to our researchers along with a description of why they had chosen each image (interpreters were provided where necessary). A follow-up session was held consisting of each neighborhood group collectively meeting to discuss a selection of photos curated by the research team with particularly interesting and compelling photos, especially those that might reveal contested or multi-faceted uses or understandings of particular spaces. If successful, as in the examples with parent activists in LA or indigenous groups in Canada discussed earlier, Photovoice is a method that can be used to reveal the narratives, logics, ideologies, and contested visions that lie hidden within and beneath places, processes and people. Our intent at the start of this project had been to use Photovoice to identify changes that refugees and their neighbors wished to see in their communities in Vermont-what were the things they valued and how might they advocate for needs that they might articulate? Our hope, as stated previously was to have the information gleaned from this process make its way into urban development and planning via neighborhood planning assemblies, city departments, municipal councils, and other local actors with whom we might share our data.

Yet while the other elements of our overall project-interviews with key informants, mapping of settlement patterns, polling of attitudes, assessment of programs - proceeded apace, the Photovoice project has been stubbornly difficult to proceed with. Part of this is not surprising - as valuable a tool as Photovoice can be, its potential has always been balanced by ethical concerns regarding representation, voice, the permanency of the images taken, and their ultimate use, as previously discussed. In this project, as immigration became an increasingly controversial topic and refugees had an unflattering spotlight shone on them, it became harder and harder to recruit participants. There were many reasons for this, as the following quotes - all collected during the discussion groups conducted after the photo-taking had been completed and the neighborhood participants gathered with the research team to talk about what their experiences had been. More than a few people expressed discomfort at being seen in public taking pictures-would this make them appear suspicious, one asked:

I don't know-are people going to get upset if they see me walking around taking pictures of stuff? What if they ask who's that brown guy and why's he taking pictures of that building? What if they say I'm a terrorist? 
Another wondered whether authorities would question his activities:

So do you guys tell the police what we're doing? We have enough problems with them. What do I say if they ask me why I'm taking pictures? Are they going to believe me if I say it's for a university project?

Many participants suggested that they did NOT want their photos or descriptions publicly shared-as had been originally envisioned in the form of a community event or gallery showing. Some who eventually ceased participation were even unsure about sharing their images and thoughts with other refugees even within the context of the project. Our team members also began to notice a significant discrepancy between the quality of pictures taken outside and inside. The former were often blurry and of poor quality, clearly taken in a hurried fashion, while the latter were often much crisper, clearer and more vibrant. During one of our first group discussions we asked about the difference directly. One participant said.

It's because I' $m$ taking those from a car, quickly, as we drive by. Inside I don't worry what someone's going to think if they see me taking a picture.

\section{Another said.}

Well, when I take pictures walking down the street I sort of pretend like I'm doing something else on my phone, like looking something up. So I take the picture quickly and I don't really have time to line anything up. It's easier that way, nobody thinks if I'm just on my phone. You know, it's like if you want to take a picture of someone famous you do that.

We thus began to alter our instructions and our practices for the Photovoice project. We encouraged participants to travel in pairs or groups when taking photos and said that we were fine with blurry pictures and the practices they used to conceal their activities. We also provided business cards with contact information for the research team for participants to carry and spoke with the police departments in the neighborhoods in question about what they were doing. We provided research team members to accompany participants as well if they so desired. Again, the solutions here are inelegant and imperfect-participants working together might influence each other's answers, as might also be the case if a participant traveling with a research team member might seek to provide the answers they think are being sought. Yet these alterations to our practices provided at least some sense of security to our participants.

The need to modify our processes as the literature on the successful use of Photovoice and temper our expectations of outcomes became readily apparent to us. Our participants also provided us important lessons on Harley's description of photography as a practice of power-we needed to be reminded that who holds a camera and how they are perceived are not neutral components of the method. Additionally, the meaning of what exploitation might mean in terms of not only the use of an image but even the taking of a picture was something I had clearly not thought through. In one case, for example, a participant had insisted on taking posed pictures of individuals in front of their homes or businesses (despite our express instructions to not take pictures of people or faces). The participant had done so for what he considered positive reasons-he was proud of these individuals and saw them as success stories within his community and neighborhood. But during the group discussion of the images he was upset to see that we had blurred the actual images of people as we considered the photos-undermining his purpose in taking them. Additionally, a number of other participants raised concerns with him in that meeting, with one saying.

You should not have taken photos like that. Many people were upset. You are young but if you were older you would know that before we were forced to leave Bhutan, the government came and took pictures of us in front of our shops and homes. And then they made a list of all of us and then they forced us to leave the country. When you took those pictures you made some of the elders think of that, when that happened.

Such a dynamic brings to mind the cautions regarding vicarious and secondary trauma that the Photovoice method might unintentionally engender (Creighton et. al. 2018). There were multiple such lessons that I took from the experience of conducting this Photovoice project. 


\section{Conclusion}

In the end, what lessons would I draw from my use of Photovoice in this particular context? Conducting research in a manner that is respectful, reciprocal and collaborative is as challenging as it is necessary, as the literature from a range of disciplines and the examples described in this paper illustrate all too well. The tensions that exist at any time are especially sharpened and intensified during turbulent times, especially when the communities one studies and/or works with may feel especially vulnerable for any number of reasons. Even the best of intentions cannot prevent misunderstandings, miscommunication and frustrations from arising. It is thus incumbent upon us as researchers to prepare as completely as possible and to learn from our mistakes and the best practices of others. In the context of refugee research in an era of rising xenophobia, the protection of participant data and identities, the impact of even putatively benign activities upon those we work with, and a commitment to pursuing shared mutually beneficial research design and outcomes become all the more important.

I will end this article with two concrete steps we have taken within our research project and with our partners to improve our practices, initiatives that may be useful to others pursuing community-based research projects. The first has been the building of a refugee research network between my colleagues and myself. It began as a loose affiliation of those who found themselves working on projects with various communities in disciplines across campus-geography, education, medicine, public health, agriculture, and environmental studies among them. We modeled ourselves after other similar networks operating in other institutions (especially the Refugee Research Network based at York University, Canada with partners across the world). Such a network had three main functions: (1) develop research projects in collaboration with community partners and make the results easily accessible to them, (2) train and support faculty and students to in turn better manage community relationships and lessen research fatigue, and (3) make practical and useful interventions in public policy debates and discourse. Our results have at this nascent stage been promising, leading to several joint projects with community partners on topics they have identified as important to them.
Examples include efforts to reduce racial disparities in the criminal justice system for refugee youth, cold weather agriculture for refugee farmers, addressing food insecurity in some of the communities, and strengthening parent education for refugee families in local school districts. We have also developed guides and pathways for both students and faculty interested in working with refugees, including appropriate coursework and volunteer experience for the former and fieldwork guides and professional development opportunities for the latter. The use of Photovoicewhether the actual images taken by participants in our project, or the discussion of the techniques-has sometimes been unexpected. While our research team has presented some suggestions to our partners about how to translate findings into policy or action, the most promising and productive directions have come from participants themselves. Some have, for example, suggested using photographs taken by them of their preferred shelf-stable foods in neighborhood ethnic grocery stores to indicate to local food banks what they should provide for refugee families. Others have discussed uploading their images of cracked sidewalks and roadways in need of repair to municipal public works' websites, utilizing an online reporting system called "See Click Fix" that has been popular with the general public but is generally underused by the refugee communities. Yet others have suggested overcoming linguistic barriers in community gardens and farm plots by posting signage based on photos they have taken to inform each other (and garden managers) about pest problems, invasive species and equipment failures.

More importantly, several of the community partners themselves have taken up the task of setting the conditions for collaboration with university researchers. The refugee agriculture program discussed in this paper for example, has developed a model and set of questions that is now required by any researcher seeking to work with them. The minimum requirements now include a demonstration that the proposed work does not repeat existing research, that compensation for staff and participant time has been built into the budget, and that the research team has completed adequate background research into the communities they seek to work with. The organization has drawn on similar partnership frameworks developed by indigenous communities in Canada, the US and Australia as templates. Other refugee organizations and agencies 
have embarked upon similar initiatives-students seeking to intern with them must now demonstrate their preparedness for working with communities through volunteer hours and coursework, for example. Efforts such as these cannot guarantee that problems will not arise, and they will not change the broader context of an anti-immigrant atmosphere. But they can offer some suggestions for how to think about ethical practices in studying, teaching and learning with refugee communities in the contemporary moment.

Funding The study on which this article is based was funded by the National Science Foundation (Award \#1359895).

\section{Compliance with ethical standards}

Conflict of interest The authors declare they have no conflicts of interest.

Ethical approval The research involving human participants on which this article is based has been approved by the University of Vermont's Institutional Review Board (Protocol CHRBS 14-487).

\section{References}

Alderman, D., \& Inwood, J. (2019). The need for public intellectuals in the Trump Era and beyond: Strategies for communication, engagement, and advocacy. The Professional Geographer, 71(1), 145-151.

Bain, A., Payne, W., \& Isen, J. (2014). Rendering a neighbourhood queer. Social \& Cultural Geography, 16(4), $1-20$.

Bengle, T., \& Schuch, C. (2018). Integrating participatory action research into graduate geography studies: A tale of two dissertations. Journal of Geography in Higher Education, 42(4), 617-629.

Borowiak, C., Safri, M., Healy, S., \& Pavlovskaya, M. (2018). Navigating the fault lines: Race and class in Philadelphia's solidarity economy. Antipode, 50(3), 577-603.

Bose, P. (2018). Welcome and hope, fear and loathing: The politics of refugee resettlement in Vermont. Peace and Conflict: Journal of Peace Psychology, 24(3), 320-329.

Browne, K. (2005). Snowball sampling: Using social networks to research non-heterosexual women. International Journal of Social Research Methodology, 1464-5300(8), 47-60.

Bryan, J. (2016). Geography and the military: Notes for a debate. Annals of the American Association of Geographers, 106(3), 506-512.

Bose, P. (2020). Refugees in new destinations and small cities: Resettlement in Vermont. Singapore: Palgrave MacMillan.

Burke, K., Greene, S., \& McKenna, M. (2016). A critical geographic approach to youth civic engagement: Reframing educational opportunity zones and the use of public spaces. Urban Education, 51(2), 143-169.
Cammarota, J. (2017). Youth participatory action research: A pedagogy of transformational resistance for critical youth studies. Journal for Critical Education Policy Studies., 15(2), 190-213.

Castledon, H., Garvin, T., \& Nation, H.-a-A. (2008). Modifying photovoice for community-based participatory indigenous research. Social Science \& Medicine, 66(2008), 1393-1405.

Chambers, R. (1994). The origins and practice of participatory rural appraisal. World Development, 22(7), 953-969.

Clark, T. (2008). 'We're over-researched here!' Exploring accounts of research fatigue within qualitative research engagements. Sociology, 42(5), 953-970.

Creighton, G., Oliffe, J., Ferlatte, O., Bottorff, J., Broom, A., \& Jenkins, E. (2018). Photovoice ethics: Critical reflections from men's mental health research. Qualitative Health Research, 28(3), 446-455.

Cronin-Furman, K., \& Lake, M. (2018). Ethics abroad: fieldwork in fragile and violent contexts, PS: Political Science \& Politics. 51(3), 607-614.

da Silva Vieira, R., \& Antunes, P. (2014). Using photo-surveys to inform participatory urban planning processes: Lessons from practice. Land Use Policy, 38(2014), 497-508.

Derr, V., \& Simons, J. (2019). A review of photovoice applications in environment, sustainability and conservation contexts: Is the method maintaining its emancipatory intents? Environmental Education Research, 26(3), 359-380.

Dyer, S., \& Demeritt, D. (2009). Un-ethical review? Why it is wrong to apply the medical model of research governance to human geography. Progress in Human Geography, 33(1), 46-64.

Fotheringham, S., Walsh, C., \& Burrowes, A. (2014). "A place to rest": The role of transitional housing in ending homelessness for women in Calgary, Canada. Gender, Place and Culture, 21(7), 834-853.

Fujii, L. (2012). Research ethics 101: Dilemmas and responsibilities. PS: Political Science Politics, 45(4), 717-723.

Fusco, C., Moola, F., Faulkner, G., Buliung, R., \& Richichi, V. (2012). Toward an understanding of children's perceptions of their transport geographies: (non)active school travel and visual representations of the built environment. Journal of Transport Geography, 20(1), 62-70.

Goessling, K. (2018). Increasing the depth of field: Critical race theory and photovoice as counter storytelling praxis. $U r$ ban Review: Issues and Ideas in Public Education, 50(4), 648-674.

Greene, S., Burke, K., \& McKenna, M. (2013). Forms of voice: Exploring the empowerment of youth at the intersection of art and action. The Urban Review, 45(3), 311-334.

Hale, C. R. (2006). Activist research v. cultural critique: Indigenous land rights and the contradictions of politically engaged anthropology. Cultural Anthropology, 21(1), 96-120.

Harley, A. (2012). Picturing reality: Power, ethics and politics in using photovoice. International Journal of Qualitative Methods, 11(4), 320-339.

Hawthorne, T., \& Kwan, M.-P. (2012). Using GIS and perceived distance to understand the unequal geographies of healthcare in lower-income urban neighborhoods. The Geographical Journal, 178(1), 18-30. 
Hawthorne, T., Solís, P., Terry, B., Price, M., \& Atchison, C. (2015). Critical reflection mapping as a hybrid methodology for examining sociospatial perceptions of new research sites. Annals of the Association of American Geographers, 105(1), 22-47.

Holt, L., Jeffries, J., Hall, E., \& Power, A. (2019). Geographies of co-production: Learning from inclusive research approaches at the margins. Area, 51(3), 390-395.

Kindon, S., \& Elwood, S. (2009). Introduction: more than methods-reflections on participatory action research in geographic teaching, learning and research. Journal of Geography in Higher Education, 33(1), 19-32.

Kindon, S., Pain, R., \& Kesby, M. (Eds.). (2007). Participatory action research and methods: Connecting people, participation and place. New York: Routledge.

Kirsch, S. (2018). Engaged anthropology: Politics beyond the text. Oakland: University of California Press.

Kyriakides, C., Bajjali, L., McLuhan, A., \& Anderson, K. (2018). Beyond refuge: Contested orientalism and persons of self-rescue. Canadian Ethnic Studies, 50(2), 59-78.

Landau, L. (2019). Capacity, complicity and subversion: Revisiting collaborative refugee research in an era of containment. In S. McGrath \& J. Young (Eds.), Mobilizing global knowledge: Refugee research in an age of displacement (pp. 25-43). Calgary: University of Calgary Press.

Lester, A. (2016). Settler colonialism, george grey and the politics of ethnography. Environment and Planning D: Society and Space, 34(3), 492-507.

Merrick, M. (2012). Clarendon and Portsmouth, North Portland photovoice project, 2008: Exploring challenges to healthy living. Portland: National Neighborhood Indicators Partnership.

Mirsepassi, A., Basu, A., \& Weaver, F. (Eds.). (2003). Localizing knowledge in a globalizing world: Recasting the area studies debate. US: Syracuse University Press.

Mollett, S. (2013). Mapping deception: The politics of mapping Miskito and Garifuna space in Honduras. Annals of the Association of American Geographers, 103(5), 1227-1241.

Murray, L., \& Nash, M. (2017). The challenges of participant photography: A critical reflection on methodology and ethics in two cultural contexts. Qualitative Health Research, 27(6), 923-937.

Neal, S., Mohan, G., Cochrane, A., \& Bennett, K. (2016). 'You can't move in hackney without bumping into an anthropologist': Why certain places attract research attention. Qualitative Research, 16(5), 491-507.

Pain, R. (2004). Social geography: participatory research. Progress in Human Geography 28(5), 652-663.

Pérez, M., Ruiz Guerrero, M., \& Mora, E. (2016). Black feminist photovoice: Fostering critical awareness of diverse families and communities in early childhood teacher education. Journal of Early Childhood Teacher Education, 37(1), 41-60.

Randa Nucho, J., \& Nahm, S. (2018). Collaborative visual methods: Parent activism, educational justice, and photography in a Los Angeles Elementary School. Human Organization, 77(3), 228-238.

Rania, N., Migliorini, L., Rebora, S., \& Cardinali, P. (2014). Enhancing critical dialogue about intercultural integration: The photovoice technique. International Journal of Intercultural Relations, 41(2014), 17-31.
Robinson, J. (2011). Points, lines and people: Plotting a course for community geography. Public presentation, October 15, 2011. University of Vermont.

Robinson, J., Block, D., \& Rees, A. (2017). Community geography: Addressing barriers in Public Participation GIS. The Cartographic Journal, 54(1), 5-13.

Robinson, J., \& Hawthorne, T. (2018). Making space for community-engaged scholarship in geography. The Professional Geographer, 70(2), 277-283.

Ronzi, S., Pope, D., Orton, L., \& Bruce, N. (2015). Towards healthy ageing in urban environments: Engaging older people and stakeholders in strengthening respect and social inclusion in cities using photo-voice participatory methods. Journal of Epidemiological Community Health, 69(Supplemental 1), A1-A90.

Rose, G. (1997). Situating knowledges: Positionality, reflexivities and other tactics. Progress in Human Geography, 21(3), 305-320.

RPC. (2020). Historical arrivals broken down by region (1975present). Refugee Processing Center. Available from https://www.wrapsnet.org/documents/Refugee $\%$ 20Admissions $\% 20$ by $\% 20$ Region $\% 20$ since $\% 201975 \%$ 20as\%20of \%2010-5-20.pdf.

Rubin, A., \& Babbie, E. (Eds.). (2011). Research methods for social work. Belmont, CA: Brooks/Cole.

Sanon, M., Evans-Agnew, R., \& Boutain, D. (2014). An exploration of social justice intent in photovoice research studies from 2008 to 2013. Nursing Inquiry, 21(3), 212-226.

Sharp, J. (2005). Geography and gender: Feminist methodologies in collaboration and in the field. Progress in Human Geography, 29(3), 304-309.

Sukarieh, M., \& Tannock, S. (2013). On the problem of overresearched communities: The case of the Shatila Palestinian refugee camp in Lebanon. Sociology, 47(3), 494-508.

UNHCR. (2020). Figures at a glance. Accessed January 26, 2020. Available from https://www.unhcr.org/en-us/figuresata-glance.html

US Census Bureau. (2020). Quickfacts Vermont. Available from https://www.census.gov/quickfacts/VT.

Valentine, G. (2005). Geography and ethics: Moral geographies? Ethical commitment in research and teaching. Progress in Human Geography, 29(4), 483-487.

Villenas, S. (1996). The colonizer/colonized Chicana ethnographer: Identity, marginalization, and co-optation in the field. Harvard Educational Review, 66(4), 711-732.

Wainwright, J., \& Bryan, J. (2009). Cartography, territory, property: postcolonial reflections on indigenous countermapping in Nicaragua and Belize. Cultural Geographies, 16(2), 153-178.

Wang, C. C., \& Burris, M. A. (1997). Photovoice: Concept, methodology and use for participatory needs assessment. Health Education \& Behaviour, 24(1997), 369-387.

Wilson, M. (2009). Towards a genealogy of qualitative GIS. In M. Cope \& S. Elwood (Eds.), Qualitative GIS: A mixed methods approach (pp. 156-170). Los Angeles: Sage.

Publisher's Note Springer Nature remains neutral with regard to jurisdictional claims in published maps and institutional affiliations. 